\title{
REFLEXÕES SOBRE A ONEROSIDADE E A NATUREZA JURÍDICA DA CONTRAPRESTAÇÃO FINANCEIRA PAGA EM RAZÃO DO PACTO DE NÃO CONCORRÊNCIA
}

\author{
Flávia Amaral Sete* \\ Ricardo José Leite de Sousa*
}

\section{RESUMO}

O presente artigo analisa o instituto do pacto de não concorrência, indagando se a onerosidade é indispensável à validade do pacto. Também almeja analisar a natureza jurídica da contraprestação financeira paga em razão do pacto, tentando responder se sua natureza é a de compensação pela perda de uma chance. Para a investigação, realizou-se uma pesquisa qualitativa, com base em estudo de textos científicos, legislativos e decisões judiciais, pelo método de análise de conteúdo, utilizando-se como técnica a análise de documentação indireta e a bibliográfica.

Palavras-Chaves: Pacto de não concorrência. Relação de Emprego. Onerosidade. Indenização. Perda da chance.

\section{THOUGHTS ON THE COSTLY NATURE AND LEGAL NATURE OF THE FINANCIAL COMPENSATION RESULTING FROM THE NON-COMPETE PACT}

\begin{abstract}
The present article aimes to analyze the institute of the non compete pact, inquiring if the costly nature is indispensable to it's legal validity. It also aims to analyze the legal nature of the financial compensation paid, trying to respond if its nature is to compensate for the loss of a chance. For the investigation, a qualitative research was carried out, based on a study of scientific, legislative and judicial texts, using the content analysis method, indirect and bibliographic documentation as a technique.
\end{abstract}

Keywords: Non-compete pact. Employment relationship. Costly Nature. Damages Compensation. Loss of a chance.

\section{INTRODUÇÃO}

\footnotetext{
* Mestre em Direito do Trabalho e Direito Previdenciário pela Universidade do Estado do Rio de Janeiro (UERJ). 2019. Pós-graduanda, em Direito do Trabalho e Processo do Trabalho.2017, Advogada Trabalhista. E-mail: flaviasette@uol.com.br

* Doutorando em Direito do Trabalho e Direito Previdenciário pela Universidade do Estado do Rio de Janeiro. (UERJ). 2019. Graduado em Direito pela Universidade Federal do Rio de janeiro. 2001.Pós-graduado em Direito do Trabalho pela Universidade Gama Filho - UGF, 2009 Advogado Trabalhista. Sócio do Escritório Loureiro Maia
} 
A preocupação com a concorrência desleal permeia diversos campos do Direito no ordenamento brasileiro, sendo verificada desde a tipificação do crime de concorrência desleal, previsto no artigo 195 da Lei $\mathrm{n}^{\circ}$ 9.279/1996; passando pelas restrições impostas ao sócio retirante, que é obrigado a não atuar em sociedade empresária concorrente ou é submetido a uma limitação espacial para o exercício de sua atividade empresarial, de acordo com a dicção do artigo 1.147 do Código Civil de 2002 e chegando ao Direito do Trabalho, em que há previsão para rescisão contratual por justa causa do empregado, quando se verifica prática de ato de concorrência ao seu empregador (artigo 482, alínea “c”, da Consolidação das Leis do Trabalho) ou de ato que viole segredo da empresa (artigo 482, alínea "g”, da Consolidação das Leis do Trabalho).

Relativamente à preservação de informações sigilosas e de segredo de negócio, mediante a celebração de pacto de não concorrência após a rescisão do contrato de trabalho, matéria sobre a qual se estrutura o presente estudo, observa-se que a globalização da economia impõe um modelo de tamanha competitividade que faz com que a relação de emprego assuma um elevado grau de complexidade, especialmente no que se refere aos empregados que têm acesso a informações importantes para a manutenção e disputa dos mercados em que seus empregadores estão inseridos.

Objetivando manter ou atrair clientela, bem como conquistar novos mercados, procura-se não só a proteção das técnicas utilizadas na produção, mas também evitar que exempregados que tiveram acesso a informações que possuam valor concorrencial venham a propagar o conhecimento adquirido de forma indevida, trazendo prejuízo ao antigo empregador.

O estudo ora apresentado tem por objetivo, de modo geral, analisar a relação existente entre a concorrência e o contrato de trabalho, discutindo se, para que haja validade da cláusula contratual de não concorrência após a extinção do contrato de trabalho é necessário o pagamento de uma compensação financeira.

Concluindo-se que a compensação é indispensável á validade do pacto, o estudo almejará compreender sua natureza jurídica, buscando responder se ela se perfaz em uma indenização pela perda da chance.

Para tanto, realiza-se uma pesquisa interdisciplinar, que coordena conteúdos de Direito da Propriedade Industrial, Direito da Concorrência e Direito do Trabalho, a partir de um método dedutivo de análise de conteúdo, por meio de documentação indireta. 
Tendo em vista os objetivos traçados, procede-se a análise de textos teóricos e legais, pátrios e estrangeiros, a fim de se investigar a relação existente entre segredo de negócio e informações sigilosas, a concorrência e a relação de emprego, valendo-se da revisão de literatura.

Para maior clareza, informa-se que ao longo do estudo o pacto de não concorrência será referido também como cláusula de não concorrência, sendo que os dois termos serão apresentados como sinônimos, tendo um mesmo propósito.

O artigo será dividido em cinco partes.

Na primeira será abordado o conceito de cláusula de não concorrência.

Na segunda parte será abordada a relação existente entre o pacto de não concorrência e o contrato de emprego.

Na terceira parte será feita uma abordagem geral sobre os requisitos de validade da cláusula de não concorrência.

Na quarta parte será abordada a onerosidade.

Na quinta parte será abordada a natureza jurídica do valor recebido pelo empregado de seu empregador com relação à cláusula de não concorrência, bem como será avaliada a relação dessa natureza com a teoria da perda de uma chance.

\section{0 conceito do pacto de não concorrência}

É imperioso compreender em que consiste o pacto de não concorrer.

Alguns autores definem o pacto de não concorrência como a obrigação, em virtude da qual o empregado se compromete a não praticar, por conta própria ou alheia, após a vigência do contrato de trabalho, ação que implique desvio de clientela de seu antigo empregador (BELTRAN, 2002, p.421).

Tal definição não nos parece a mais adequada, haja vista que os atos de concorrência não se limitam, exclusivamente, àqueles relacionados ao desvio de clientela.

De fato, a concorrência pode ser implementada por diversas maneiras, como, por exemplo, através da divulgação de métodos produtivos, custos operacionais, fórmulas etc. 
A cláusula consiste na obrigação de abstenção do empregado de ativar-se por conta própria ou para outro empregador, em atividade igual ou semelhante, após o término do contrato de trabalho, que se afigura mais adequada.

Nota-se que, da parte do trabalhador, é assumida uma obrigação de não fazer, que consiste na abstenção em praticar um ato, podendo ser limitada ou não no tempo.

A obrigação de não fazer tem por fim impedir que o devedor pratique ato que teria o direito de realizar se não tivesse se obrigado a abster-se, impingindo autorrestrição à sua liberdade pessoal (GOMES, 2005, p.40).

Caio Maio Pereira ilustra a questão ensinando que “[...] a obrigação de não fazer é a negativa típica. O devedor obriga-se a uma abstenção, conservando-se em uma situação omissiva. A sua prestação é o non facere, seja mediante uma contraprestação, seja independente dela" (PEREIRA, 2004,p 64).

Destarte, as obrigações de não fazer são caracterizadas por uma prestação negativa, por uma conduta omissiva. A abstenção objeto da obrigação deverá ocorrer durante um período, sendo que, em nosso ordenamento, a questão é regulada pelos artigos 250 e 251 do Código Civil (BRASIL, 2002) ${ }^{1}$.

No caso específico do pacto de não concorrência, a obrigação de não fazer assumida pelo trabalhador consiste na restrição à sua liberdade de trabalho, que ficará limitada em relação a atividades profissionais em que haja colisão de interesses concorrenciais ao antigo empregador.

A proibição decorrente do pacto não se limita ao exercício contínuo de atividades que signifiquem concorrência ao ex-empregador. Mesmo atividades pontuais, como, por exemplo, a execução de um único projeto, estão abarcadas pela restrição, uma vez que podem significar risco tão ou mais deletério do que aquelas advindas de uma atividade rotineira (OLIVEIRA, 1937, p.139).

Além disso, a atividade concorrencial objeto de impedimento não está restrita àquela que o trabalhador pode exercer em um novo emprego. Com efeito, o trabalho autônomo, ou mesmo a constituição de uma sociedade empresária por parte do antigo empregado, que tenha

\footnotetext{
1 “Art. 250. Extingue-se a obrigação de não fazer, desde que, sem culpa do devedor, se lhe torne impossível abster-se do ato, que se obrigou a não praticar."

“Art. 251. Praticado pelo devedor o ato, a cuja abstenção se obrigara, o credor pode exigir dele que o desfaça, sob pena de se desfazer à sua custa, ressarcindo o culpado perdas e danos.

Parágrafo único. Em caso de urgência, poderá o credor desfazer ou mandar desfazer, independentemente de autorização judicial, sem prejuízo do ressarcimento devido.”
} 
por objetivo exercer a atividade cuja proibição foi pactuada são alcançados pelos efeitos da cláusula de não concorrência.

Assim, cabe verificar se a assunção desse impedimento é consentânea com as normas que regem as relações e trabalho em âmbito nacional.

Primeiramente, impõe-se analisar os dois argumentos normalmente expostos para que a cláusula de não concorrência seja vista como inválida ou mesmo ilícita.

O primeiro argumento, o mais repetido, é o de que o impedimento assumido pelo empregado atenta contra o direito constitucionalmente garantido à liberdade de trabalho. Como visto, exaustivamente, tal argumento não se sustenta.

O segundo, e a nosso ver mais simplório, é o de que a legislação nacional não autoriza tal pactuação.

Data venia dos que defendem tal argumento, verifica-se uma verdadeira subversão da lógica jurídica.

Como regra, tudo aquilo que não é vedado pelo ordenamento jurídico deve ser visto como permitido ${ }^{2}$.

Aqui, expõe-se raciocínio justamente em sentido inverso.

Essa ordem de ideias demonstra uma excessiva dependência da positivação das normas. Segundo esse raciocínio, o que não é previsto pelo legislador, válido não será.

Trata-se de abraçar, de forma desmedida, o positivismo jurídico, redundando em uma idolatria das leis e códigos como única fonte admissível para o Direito.

Contudo, a sociedade caminha a passos largos à frente do legislador, que é incapaz de prever e regulamentar todas as situações da vida cotidiana.

Portanto, o fato de inexistir norma que regule expressamente a celebração do pacto de não concorrência não significa, per se, que ela seja incompatível com o restante do ordenamento jurídico vigente.

Pelo contrário. Todo negócio jurídico que seja celebrado por agentes capazes, tendo objeto lícito, possível, determinado ou determinável e que não tenha sua forma defesa em lei será válido, conforme o disposto no artigo 104 do Código Civil (BRASIL, 2002).

\footnotetext{
${ }^{2}$ Essa é a regra do artigo 122 do Código Civil:

“Art. 122. São lícitas, em geral, todas as condições não contrárias à lei, à ordem pública ou aos bons costumes; entre as condições defesas se incluem as que privarem de todo efeito o negócio jurídico, ou o sujeitarem ao puro arbítrio de uma das partes."
} 


\section{A relação existente entre o pacto de não concorrência e o contrato de emprego.}

Faz-se necessário estabelecer a relação existente entre o pacto de não concorrência e o contrato de emprego.

O primeiro aspecto relevante é o de que as cláusulas do pacto de não concorrência tem objeto próprio, requisitos específicos, e não necessariamente o pacto precisa ser simultaneamente celebrado com o contrato de trabalho.

Mesmo sendo celebrados dois contratos, o de não concorrer é unilateralmente dependente do contrato de trabalho. Como consequência, a nulidade do contrato de trabalho implica a nulidade do pacto de não concorrência, mas não o inverso.

Em assim sendo, pode-se asseverar que o pacto de não concorrência celebrado em razão de um contrato de trabalho que tenha objeto ilícito (trabalhar no jogo do bicho, por exemplo) não surtirá qualquer efeito, haja vista o vício que acomete o vínculo principal.

Passados por esses esclarecimentos, restam ser analisados os seguintes aspectos: i) os sujeitos que podem celebrar a cláusula de não concorrência; ii) se existe uma forma a ser observada para a celebração da avença; iii) qual o objeto do pacto; iv) quais são suas condições de validade; v) se há alguma influência da modalidade de rescisão do contrato de emprego na eficácia do pacto; vi) se há possibilidade de denúncia unilateral do pacto e de renúncia aos direitos dele advindos; vii) quais são os efeitos do inadimplemento das obrigações assumidas e, por fim, viii) quais são seus efeitos perante terceiros.

\section{Os requisitos de validade do pacto de não concorrência}

O primeiro dos requisitos de validade guarda relação com a legitimidade inerente às partes.

Em relação aos sujeitos que podem avençar a cláusula de não concorrência, a primeira ideia que vem à mente é a que sua celebração depende da existência de um contrato de emprego que lhe seja anterior. Segundo essa ótica, o pacto necessariamente deveria ser celebrado por empregado e empregador.

O segundo requisito guarda relação com o momento de celebração, na admissão e demissão do empregado. 
Por isso, vê-se com certa tranquilidade a afirmação de Egon Felix Gottschalk de que o pacto de não concorrência tem sua origem no próprio contrato de trabalho, eis que apenas um vínculo de emprego anterior justificaria sua celebração, já que ele seria o nascedouro para os conhecimentos e segredos transmitidos para o empregado, cujo uso em prol de concorrentes quer se evitar (GOTTSCHALK, 1970, p.785).

Da mesma maneira, é possível que a celebração ocorra quando já extinto o contrato de emprego, o que será visto com mais detalhes adiante.

O terceiro requisito guarda relação com o ônus probatório que o empregado possui para demonstrar que houve um vício de vontade. Não é razoável simplesmente presumir que o trabalhador teve sua vontade viciada, cabendo-lhe, em hipótese de alegação neste sentido, o ônus de demonstrar suas assertivas.

O quarto requisito guarda relação com a forma que deve ser observada para sua utilização. Considerando-se as peculiaridades envolvidas, bem como o fato de se tratar de um regime de exceção, a celebração do pacto de não concorrência por escrito é mais do que recomendável.

Contudo, ante a inexistência de legislação específica regulamentando a matéria, fazse necessário observar os regramentos gerais que dispõem sobre a celebração dos contratos.

A regra do artigo 107 do Código Civil é de que "a validade da declaração de vontade não dependerá de forma especial, senão quando a lei expressamente a exigir" (BRASIL, 2002).

Já o artigo 166, inciso V, do mesmo diploma legal, disciplina que o negócio jurídico será nulo quando abdicar de alguma formalidade imposta em lei(BRASIL, 2002).

Entretanto, no caso dos contratos de trabalho, a celebração por escrito não é exigível, de acordo com o que preceitua o caput do artigo $442^{3}$ da CLT (BRASIL, 1943).

Por essas razões, Oris de Oliveira concluiu que "não havendo no direito brasileiro disciplina heterônoma sobre a matéria, a rescisão ou nulidade não ocorrerá em razão da forma" (OLIVEIRA, 1937, p.153).

O quinto requisito prescreve a necessidade de delimitação do objeto, sendo certo que a cláusula de não concorrência não pode significar o absoluto impedimento ao exercício de todo e qualquer tipo de trabalho.

\footnotetext{
3“Art. 442 - Contrato individual de trabalho é o acordo tácito ou expresso, correspondente à relação de emprego.” BRASIL. Lei n ${ }^{\circ} 5.452$ de $1^{\circ}$ de maio de 1943.
} 
O sexto requisito inerente a validade da cláusula em destaque guarda ligação com a delimitação geográfica dela.

Tratando-se de atividade econômica que, por sua própria natureza, tenha uma limitação geográfica clara, não há muita indagação quanto à necessidade de o pacto ser limitado à mesma região.

O sétimo requisito guarda relação com o caráter temporal de fixação de efeitos para a prevalência da cláusula.

Da mesma maneira que não se pode admitir a celebração de pacto de não concorrência que implique a completa impossibilidade de trabalhar, tampouco é possível consentir que o impedimento tenha duração ilimitada.

O presente estudo buscou abordar alguns dos requisitos de validade do pacto de não concorrência de forma geral.

No próximo tópico será dado maior enfoque ao requisito ligado a onerosidade, tema central do presente estudo, tendo em vista a relevância do estudo de sua natureza jurídica, bem como a compreensão da razão desse requisito promover uma mitigação a liberdade de ofício ou profissão, que é uma garantia constitucionalmente assegurada.

\section{A onerosidade}

Nesse ponto, prevalece o entendimento de que o pacto de não concorrência só será válido se for oneroso para o antigo empregador.

Entretanto, o pagamento em favor do ex-empregado nem sempre foi visto como requisito de validade para a exigência de quarentena.

Oris de Oliveira informa que se percorreu um longo caminho até que se chegasse à conclusão de ser necessário o pagamento de uma contraprestação pelo impedimento imposto ao trabalhador, tendo havido um tempo em que lojas de Paris e Berlim inseriam no contrato de trabalho de seus empregados cláusula proibindo que viessem a trabalhar para a concorrência no futuro, sem que houvesse qualquer pagamento por isso (OLIVEIRA, 1937, p.144)..

Hoje, a questão é vista com outros olhos em quase todos os lugares. 
Da mesma forma, os doutrinadores pátrios defendem que a onerosidade é condição sine qua non de validade da cláusula de não concorrência ${ }^{4}$.

É interessante registrar que não obstante haja hoje no Brasil um vácuo legislativo sobre a matéria, houve no passado tentativas de dispor normas que tratassem do tema.

No mês de setembro do ano de 1979, a Portaria n ${ }^{\circ}$ 542/1979 dos Ministros da Justiça e do Trabalho criou uma Comissão Interministerial, tendo seus trabalhos capitaneados por Arnaldo Süssekind, visando à atualização da CLT e que redundou em um anteprojeto de uma nova Consolidação ${ }^{5}$.

De acordo com as considerações preliminares do relatório elaborado pela Comissão $\underline{6}$

A atualização preconizada pela referida Portaria haveria, portanto, de ter por base a própria CLT e as demais normas legais trabalhistas em vigor, a fim de ordená-las, de forma sistematizada, e clarificá-las, para dirimir dúvidas verificadas na sua aplicação.

Entretanto, contrariamente ao o que o trecho acima leva a crer, o anteprojeto elaborado não se limitou a organizar e sistematizar normas existentes. De fato, o propósito foi também o de atualizar a legislação e fazê-la avançar em campos até então não explorados ou delimitados, o que foi expressamente reconhecido nas considerações iniciais do relatório já mencionado ${ }^{\underline{7}}$

Sublinhe-se, repetindo-se o que disse a comissão elaboradora da atual CLT, que consolidar não significa apenas juntar eis e vigor, ainda que e obediência a um sistema; não corresponde ao engenho de arquitetura legislativa, mas à recapitulação e atualização dos valores coerentes resultantes de uma grande expansão legislativa anterior, num determinado ramo de Direito.

Na sequência, as considerações preliminares também consignam que ${ }^{\mathbf{8}}$

Para a elaboração do anteprojeto, a Comissão fixou as seguintes metas:

$[\ldots]$

c) aprimorar conceitos, tendo em vista a doutrina contemporânea prevalente, compatível com o sistema jurídico consubstanciado na Constituição Brasileira;

$[\ldots]$

e) aperfeiçoar regimes e instituições jurídico-trabalhistas, alterando para esse fim, em caráter excepcional, disposições legais em vigor.

\footnotetext{
${ }^{4}$ A título de exemplo pode-se citar SANTOS, João Batista dos; SILVA, Juary C. Cláusulas restritivas à liberdade de trabalho. Revista Ltr, São Paulo, v. 41, jan 1977, p. 594. OLIVEIRA, Óris de. Op. cit., p. 144.

${ }^{5}$ Cf. BRASIL. Relatório da Comissão Interministerial de Atualização da Consolidação das Leis do Trabalho. Diário Oficial da República Federativa do Brasil, Brasília, DF, 2 mai. 1979.Seção I, Parte I (Suplemento), p.1.

${ }^{6}$ Idem, ibidem.

7 Idem, p.2.

${ }^{8}$ Idem, p.3.
} 
E, com esse espírito, chega-se a justificativa para a inclusão do pacto de não concorrência no anteprojeto, feita da seguinte forma ${ }^{9}$

51. Disciplinou-se o pacto de exclusão de concorrência, previsto na legislação comparada e que vem sendo adotado por algumas empresas.

O anteprojeto em estudo decidiu adotar a nomenclatura "exclusão de concorrência" para se referir ao instituto, sendo que a existência de regulamentação da matéria em diplomas legais estrangeiros foi reconhecida pela Comissão como motivo relevante para a inclusão do tema no anteprojeto.

Curiosa, contudo, é a justificativa de que a adoção da cláusula de não concorrência por algumas empresas era uma das razões que motivara a Comissão a inserir a regulamentação no projeto legislativo.

De fato, o trabalho dirigido por Arnaldo Süssekind explicitamente visou legitimar uma medida que já vinha sendo praticada pelos empregadores brasileiros.

Essa postura encontra explicação na visão do Direito do Trabalho que é abraçada e defendida na justificação sumária do anteprojeto, o qual, em seu primeiro item, afirma que ${ }^{10}$

De acordo com o entendimento dominante na doutrina e na jurisprudência, deixou-se nítida a natureza contratual da relação de emprego. Como já ressaltou ilustre jurista francês, a idéia do contrato corresponde a uma noção central: a da liberdade do indivíduo. Dignifica, assim, a pessoa humana do trabalhador, o que constituiu a finalidade primordial do Direito do Trabalho.

A ótica contratualista do Direito do Trabalho abraçada pela Comissão encarregada de elaborar o anteprojeto explica os fundamentos utilizados para justificar a necessidade de inclusão do dispositivo em análise no âmbito da CLT.

A previsão sobre o pacto de não concorrência foi inserido no Título II do anteprojeto, que versa sobre o contrato individual de trabalho, sendo parte de seu Capítulo I, destinado a tratar das disposições gerais que devem reger o contrato de emprego.

Foi redigido para ser o artigo 26 da nova Consolidação, com o seguinte texto ${ }^{11}$ :

Art. 26. É válido o pacto de exclusão de concorrência, desde que celebrado por escrito, por período não superior a dois anos, e dele conste uma compensação mensal em favor do empregado, durante sua vigência.

Parágrafo único. O pacto deverá cingir-se ao desempenho das mesmas funções exercidas anteriormente e limitar-se a determinada área geográfica.

\footnotetext{
${ }^{9}$ Idem, p.6.

${ }^{10}$ Idem, ibidem.

11 Idem, p. 20.
} 
No projeto em análise, que não chegou a prosperar, havia previsão expressa de que o pacto só seria válido mediante o pagamento de uma compensação financeira. Ainda que a previsão não tenha sido positivada, seu espírito não deve ser abandonado.

O compromisso de não implementar concorrência ao antigo empregador, pela supressão do direito de escolher livremente onde e em que trabalhar, deve ser equilibrado com uma contraprestação que se afigure, minimamente, proporcional.

Imaginar saída diversa, significaria permitir que o conflito de interesses e direitos seja resolvido de maneira em que um dos contratantes se obrigue a uma prestação desproporcional àquela que corresponde à outra parte.

O Código Civil Brasileiro, em seu artigo 157, define a hipótese sob exame como um defeito do negócio jurídico - lesão - apto a ensejar a anulação da avença ${ }^{12}$.

Some-se a isso que a liberdade de contratar encontra limite na função social do contrato, de acordo com o artigo 421 do Código Civil ${ }^{13}$, e tal limite seria completamente desprezado se fosse admitida a pactuação de não concorrência de forma gratuita.

Não se pode perder de vista que, no caso em análise, a onerosidade da avença objetiva manter a subsistência do trabalhador durante o período em que perdurar a restrição ao trabalho.

A possibilidade de o ex-empregado se ver impedido de realizar qualquer tipo de trabalho, sem que haja uma garantia de que sua subsistência não será afetada, só poderia existir em um ordenamento jurídico em que a propriedade privada se sobrepusesse ao valor social do trabalho, sendo certo que a Constituição Federal de 1988 estabelece suas diretrizes em sentido diametralmente oposto, especialmente em seu artigo 170.

E é com esse espírito que as decisões judiciais vêm sendo proferidas no Brasil, reconhecendo que o pacto de não concorrência deve prever o pagamento de uma retribuição financeira ao empregado, sob pena de nulidade. A título exemplificativo, cita-se a ementa abaixo:

\footnotetext{
12 "Art. 157. Ocorre a lesão quando uma pessoa, sob premente necessidade, ou por inexperiência, se obriga a prestação manifestamente desproporcional ao valor da prestação oposta.

$\S 10$ Aprecia-se a desproporção das prestações segundo os valores vigentes ao tempo em que foi celebrado o negócio jurídico.

$\S 20$ Não se decretará a anulação do negócio, se for oferecido suplemento suficiente, ou se a parte favorecida concordar com a redução do proveito." BRASIL. Lei n 10.406 de 10 de janeiro de 2002. Institui o Código Civil. Diário Oficial da União. Disponível em: < http://www.planalto.gov.br/CCivil_03/leis/2002/L10406.htm>. Acesso em: 28 jun 2015

13 "Art. 421. A liberdade de contratar será exercida em razão e nos limites da função social do contrato." BRASIL. Lei ํㅡ 10.406 de 10 de janeiro de 2002. Institui o Código Civil. Diário Oficial da União. Disponível em: < http://www.planalto.gov.br/CCivil_03/leis/2002/L10406.htm>. Acesso em: 28 jun 2015
} 


\section{CLÁUSULA CONTRATUAL DE NAO-CONCORRÊNCIA SEM} RETRIBUIÇAO.NULIDADE QUE SE DECLARA. Em princípio, a cláusula de não-concorrência pode ser avençada pelas partes, exceto quando a restrição envolver verdadeira vedação a novo emprego por período indeterminado ou por termo certo, sem qualquer retribuição econômica, diante do caráter oneroso e sinalagmático do contrato de trabalho que sempre exige reciprocidade das partes. Os efeitos do contrato não podem se estender além da sua extinção, como mera restrição ao direito ao emprego. O direito ao trabalho é o da própria vida, como a forma mais honesta de sobrevivência. Não foi sem razão que a liberdade de trabalhar, "atendidas as qualificações profissionais que a lei estabelecer", foi elevada entre os direitos e garantias fundamentais, como se deduz do inciso XIII, do artigo $5^{\circ}$, da CFR. Inteligência dos artigos $3^{\circ}, 9^{\circ}$ e 444 da CLT combinado com o artigo $5^{\circ}$, XIII da CFR. (TRT-2 - RO: 1186200735102005 SP 01186-2007351-02-00-5, Relator: JOSÉ CARLOS FOGAÇA, Data de Julgamento: 19/06/2008, $7^{\text {a }}$ TURMA, Data de Publicação: $04 / 07 / 2008)^{14}$

Desta maneira, chega-se a forçosa conclusão de que a onerosidade é um requisito essencial à validade do pacto de não concorrência.

\section{6- A natureza jurídica da contraprestação decorrente da cláusula de não concorrência}

Vista a necessidade de pagamento de uma contraprestação financeira, é importante entender qual é a sua natureza jurídica, se salarial ou indenizatória.

Amauri Mascaro do Nascimento distingue salário de indenização, esclarecendo que:

A diferença entre indenização e salário se faz a partir da causa: na indenização, o dano; no salário, o trabalho prestado, a disponibilidade ao empregador ou as interrupções do trabalho nas quais a remuneração é devida.

O salário não é pago porque o trabalhador sofre um dano. É devido mesmo sem qualquer dano. A indenização não se destina a retribuir trabalho prestado, a disponibilidade ao empregador ou as interrupções do trabalho. [...]

Distinguem-se salário e indenização também segundo a finalidade dos dois institutos. A indenização visa à recomposição de um patrimônio ou de um bem jurídico. O salário não tem a finalidade de recompor patrimônio. O seu fim é pagar o trabalhador como sujeito do contrato de trabalho, acrescentando um bem econômico

\footnotetext{
${ }^{14}$ BRASIL. Tribunal Regional do Trabalho da 2aㅡ Região. Recurso Ordinário № 1186200735102005, da 7ª Turma Tribunal Regional do Trabalho da 2a ${ }^{-}$Região. Relator Desembargador José Carlos Fogaça. Processo Julgado no dia 19.06.2008, publicado no DEJT no dia 04.07.2008. Disponível em: < http://trt-

2.jusbrasil.com.br/jurisprudencia/15811916/recurso-ordinario-ro-1186200735102005-sp-01186-2007-351-02-00-5 $>$, acesso no dia 17.jul 2015.
} 
ao seu patrimônio, no sentido de entendimento de algumas das suas necessidades vitais (NASCIMENTO, 2005, p.77).

Partindo dessa premissa, interessa observar que G. H. Carmelynck sustenta que a verba paga em contrapartida à interdição ao trabalho "participa da natureza jurídica do salário, a mesmo título que a indenização do aviso prévio, embora conservando uma fisionomia original" (CARMELYNK, 1968, p.2013).

Tal definição não se mostra acertada, na medida em que, ao contrário do que ocorre com o aviso prévio, não se trata de uma indenização substitutiva (aviso prévio indenizado) a uma verba de natureza salarial (aviso prévio trabalhado).

No caso do aviso prévio, o trabalhador pode receber a verba como contraprestação ao trabalho durante esse período, ou pode ser dispensado de cumprir o pré-aviso e ser indenizado pelos valores correspondentes.

No pagamento feito em razão da cláusula de não concorrência, não há a possibilidade de o pagamento decorrer de uma prestação positiva do empregado, eis que sua razão de ser reside justamente na abstenção que se requer do laborista.

Poderia-se entender que a verba teria natureza salarial, visando remunerar tempo à disposição do empregador. Contudo, tampouco se vê correta a definição em questão, uma vez que, tendo sido rescindido o contrato de trabalho, o ex-empregado não está mais subordinado ao antigo empregador, sendo certo que não permanece à sua disposição aguardando ordens a serem cumpridas.

Mais uma vez há que se recordar que o pagamento tem como contrapartida uma abstenção do ex-empregado. Ele não autoriza que o antigo empregador exija qualquer outra coisa diferente dessa abstenção.

Se tal exigência não é possível, o trabalhador não estará aguardando algum tipo de comando do seu antigo empregador e, portanto, não estará à sua disposição.

Sendo afastadas as tentativas de atribuir natureza salarial ao pagamento, resta-lhe a natureza de indenização.

Oliveira Vianna atribui caráter indenizatório ao referido pagamento, asseverando que a interdição importa uma lesão ao patrimônio do empregado, que impõe ser reparada (VIANNA, 1937, p 16).

Sérgio Pinto Martins também adota esse entendimento (MARTINS, 2003, p.69). Contudo, não analisa de forma mais aprofundada qual seria, exatamente, o dano indenizado, sendo certo que tal questão merece uma maior reflexão. 
No caso, o dano experimentado pelo trabalhador é potencial, consubstanciado em não ter a possibilidade de se candidatar ou se tornar disponível ao exercício de determinada oportunidade de trabalho.

Diz-se potencial porque não é possível assegurar que, não fosse a interdição pactuada, o obreiro lograria êxito em conseguir o trabalho.

Sendo assim, o que se indeniza é uma perspectiva de deixar de trabalhar, ou, mais precisamente, uma oportunidade de conseguir determinado trabalho.

Por essa razão, a indenização devida ao empregado pela interdição decorrente da cláusula de não concorrência tem por objetivo compensar a perda de uma chance.

Por essa razão, Sérgio Cavalieri Filho enfatiza que, para que haja a caracterização da responsabilidade civil pela perda de uma chance, é necessário que essa chance seja efetiva, e não uma mera eventualidade, suposição ou desejo (CAVALIERI FILHO, 2012, p.81).

E essa é justamente a hipótese da indenização paga em razão do pacto de não concorrência: indeniza-se a perda da possibilidade, da chance, de o trabalhador conseguir uma nova colocação do mercado de trabalho.

\section{Conclusão}

As sociedades empresariais investem cada mais vez em desenvolvimento de novas técnicas e recursos tecnológicos, objetivando a manutenção e crescimento de sua participação nos mercados em que estão inseridas.

A par disso, estratégias de negócio montadas com base em informações sensíveis e preciosas vão alavancando o desenvolvimento de suas atividades econômicas.

Ao longo do processo produtivo e econômico, o conhecimento de técnicas, métodos, fórmulas, listas de clientes e fornecedores etc. vão sendo conferidos aos empregados, que dependem de tais informações para o exercício de suas atividades laborativas.

Tais empregados passam a ter um valor para os concorrentes de seus empregadores, que não se relaciona apenas à sua formação e preparo técnico, advindo, também, das informações sigilosas e segredos de negócio que tiveram conhecimento em razão do vínculo de emprego mantido.

Considerando-se esse estado de coisas, o presente artigo se propôs a estudar a viabilidade, pela ótica constitucional e legal, se impedir que os empregados que tenham acesso a segredos de negócio e informações sigilosas incorram em atos de concorrência aos 
seus antigos empregadores, mediante a celebração do pacto de não concorrência após o término do contrato de emprego, destacando se o pagamento de uma compensação financeira seria essencial à validade do pacto.

O estudo realizado propiciou a conclusão de que a onerosidade é um requisito essencial á celebração do pacto de não concorrência, levando à próxima indagação: qual a natureza da verba paga em contraprestação à abstenção do empregado?

Após uma análise pormenorizada, foi possível concluir que a verba paga em contraprestação ao pacto celebrado tem natureza de indenização pela perda de uma chance.

\section{Referências Bibliográficas}

BELTRAN, Ari Possidonio . Dever de fidelidade, dever de não-concorrência e cláusula de não-concorrência. Revista LTR, São Paulo, v. 66, n. 4, 2002, p. 421.

BRASIL. Lei $n^{o} 10.406$ de 10 de janeiro de 2002. Institui o Código Civil. Diário Oficial União. Disponível em: http://www.planalto.gov.br/CCivil_03/leis/2002/L10406.htm>. Acesso em: 28 jun 2015 Lei $n^{\circ} 5.452$ de $1^{\circ}$ de maio de 1943. Aprova a Consolidação das Leis do Trabalho. Diário Oficial da União. Disponível em: < http://www.planalto.gov.br/ccivil_03/decreto-lei/Del5452.htm>. Acesso em: 28 jun 2015

Relatório da Comissão Interministerial de Atualização da Consolidação das Leis do Trabalho. Diário Oficial da República Federativa do Brasil, Brasília, DF, 2 mai. 1979.Seção I, Parte I (Suplemento)

- Tribunal Regional do Trabalho da $2^{\mathrm{a}}$ Região. Recurso Ordinário $n^{o}$ 1784200604002005, da $2^{\text {a }}$ Turma Tribunal Regional do Trabalho da $2^{\text {a }}$ Região. Relator Desembargador Carlos Gomes Godoi. Processo Julgado no dia 16.09.2009, publicado no DEJT no dia 06.10.2009. Disponível em: < http://trt- 
2.jusbrasil.com.br/jurisprudencia/7523095/recurso-ordinario-record-1784200604002005-sp01784-2006-040-02-00-5 >, acesso no dia 18 jul. 2015.

CARMELYNK, G.H. Contrat de Travail. Paris: Traité de Droit de Travail, Dalloz, 1968, n. 11, p. 213 apud OLIVEIRA, Oris de. Op. cit., p. 146.

GOMES, Orlando. Obrigações. Rio de Janeiro, Editora Forense, 2005, p.40.

GOTTSCHALK, Egon Felix. A cláusula de não concorrência nos contratos individuais de trabalho. LTr, São Paulo, ano 34, nov. 1970, p. 785.

MARTINS, Sergio Pinto. Direito do Trabalho. São Paulo: Atlas, 2003, p. 139.

NASCIMENTO, Amauri Mascaro. Teoria Jurídica do Salário. São Paulo: LTr, 2005, p.77

PEREIRA,Caio Mário da Silva. Instituições de direito civil: teoria geral das obrigações. vol. II. $2^{\circ}$. ed. Rio de Janeiro: Ed. Forense, 2004, p.64.

SANTOS, João Batista dos; SILVA, Juary C. Cláusulas restritivas à liberdade de trabalho. Revista Ltr, São Paulo, v. 41, jan 1977, p. 594.

VIANNA, Oliveira. Direitos Irrenunciáveis. Sydaké. Revista dos Bancários, n. 23, 1937, p. 16 apud OLIVEIRA, Oris de. Op. cit., p. 146.

CAVALIERI FILHO, Sergio. Programa de responsabilidade civil. 10.ed. São Paulo: Atlas, 2012, p.81. 